\title{
LAS ASOCIACIONES DE LOS CRISTIANOS EN LA IGLESIA PRIMITIVA
}

\section{EL FENÓMENO ASOCIATIVO DEL IMPERIO ROMANO}

En la naturaleza humana hay una tendencia a reunirse para conseguir un objetivo común ${ }^{1}$. Entre los romanos esa inclinación se manifiesta desde los primeros tiempos de la monarquía identificado bajo el término general de collegia $^{2}$. Aunque es evidente que collega y collegium pertenecen a la misma raíz del verbo probablemente como acto de legere litteras, es decir, recoger las letras con la vista, y que ambas palabras presentan el mismo prefijo colectivo cum-, no existe, sin embargo, entre ambas palabras una correlación absoluta. Ni los collegae propiamente dichos constituyen un collegium, ni los miembros de un verdadero collegium son collegae entre sí, sino sodales o socii ${ }^{3}$.

1. El fenómeno asociativo en general. Los orígenes de los colegios hay que buscarlos en las asociaciones industriales que se remontan a la época semilegendaria del rey Numa, quien dividió al pueblo por oficios, estableciendo nueve categorías de ellos: flautistas, orfebres, carpinteros, tintoreros, zapateros, curti-

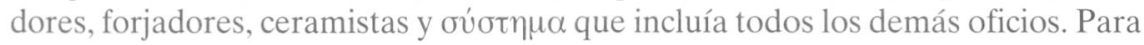
un romano el concepto de asociación no estaba bien definido por su amplitud. El concepto de asociación abarcaba desde los más amplios grupos humanos, como p. ej. el Estado, hasta las más pequeñas asociaciones populares. Es oportuno, por

${ }^{1}$ Cfr. F.M. De Robertis, Il fenomeno associativo nel mondo romano. Dai collegi della Repubblica alle corporazioni del Basso Impero, Roma 1981, 1: „La tendenza all'associazione [...] si rivela spontanea nella natura dell'uomo".

2 Otros términos indicativos de asociaciones, además del collegium son: amicitia, chorus, classis, cognatio, commune, contubernium, convictus, convivium, corpus, curia, decuria, factio,

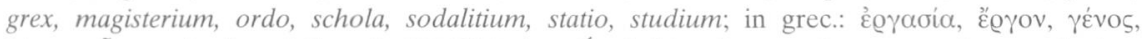

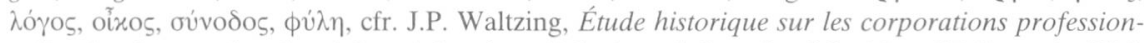
nelles chez les romains, depuis les origines jusqu'à la chute de l'empire d'Occident, IV, Louvain 1895 1900, 236-242.

${ }^{3}$ Cfr. A. D’Ors, En torno a las raíces romanas de la colegialidad, en: Tres estudios históricos sobre la colegialidad episcopal, ed. A. D’Ors - J. Orlandis - A. Hera, Pamplona 1965, 15. 
tanto, dar la distinción entre el concepto de asociación en sentido amplio y en sentido estricto. En el primer caso se trata o bien de un conjunto de hombres que, separados, persiguen un objetivo común (Estado), o bien un conjunto de hombres unidos por algún otro vínculo distinto del objetivo común (familia, habitantes de una misma región). En sentido estricto por una asociación se considera aquella surgida como resultado de una suma de voluntades reunidas libremente con un fin común y con el deseo de que su unión sea permanente ${ }^{4}$. Así se establecen multitud de asociaciones en las diversas ciudades del Imperio. Allí donde llegan las formas de vida romanas se constituyen asociaciones. Francesco M. De Robertis establece su particular clasificación. Para él existen cinco clases de asociaciones: Asociaciones profesionales. El nexo de unión de sus miembros es la coincidencia en el ejercicio de una misma profesión; Asociaciones de divertimento y convivencia; Asociaciones religiosas formadas con la intención de reunirse con el fin de honorar a una divinidad libremente elegida; Asociaciones funerarias constituidas con el fin de procurar sepultura a sus miembros y los ritos religiosos en sus exequias; Asociaciones políticas surgidas con el deseo de influir y ejercer presiones en la vida política del país ${ }^{5}$.

En el periodo monárquico aparecen las primeras asociaciones las cuales se desarrollaron durante los primeros tiempos de la república. La mayoría de los miembros de aquellas asociaciones procedían de extracción social baja: artesanos y extranjeros ${ }^{6}$. La libertad de asociaciones estaba garantizada por la Ley de las XII Tablas:

\begin{abstract}
„Son cofrades los que pertenecen a una misma asociación que los griegos llaman hetaireia. La ley les permite establecer los pactos que quieran, con tal de no infringir la ley pública. Esta ley parece copiada de la ley de Solón, que dice: 'Si no se oponen las leyes públicas sea válido lo que convienen entre sí para sus fines los de un pueblo o fratria los socios para un culto, los comensales, los cofrades de sepultura o de religión, o los que emprenden una captura o negocio"7.
\end{abstract}

Hasta la segunda mitad del siglo I a. C. las asociaciones podían desarrollarse libremente, salvo que amenazaran las leyes públicas. A finales de la república se producen las amenazas sobre el orden público que afectaban también a la vida de las asociaciones. En el año 56 a. C. hay un intento de terminar con las sodalitates mediante un senadoconsulto, pero éste no tenía éxito. Cuando César llegó al poder promulgó la lex Iulia de collegiis. Con ella se suprimía los collegia en Roma con una excepción de las antiquitas constituta, considerados como de utilidad pública. Desde el momento de la promulgación

Cfr. De Robertis, Il fenomeno associativo, p. 4-5.

Cfr. ibidem, p. 6.

${ }^{6}$ Cfr. ibidem, p. 36.

Digesta Justiniani Augusti (= Dig.) 47, 22, 4, ed. P. Bonfante - C. Fadda - L. Ferrini S. Riccobono - V. Scialoia, Mediolani 1960. 
de la lex Iulia toda asociación que deseara constituirse precisaba de la autorización del Estado. En el año 7 a. C. se vincula a los collegia al culto de los Lares Augusti y del Genius Augusti para convertirlos en un instrumento válido de lealtad al régimen vigente. Durante el periodo de vigencia de la Lex Iulia se darán pocas autorizaciones para nuevas asociaciones. Por eso los juristas levantan la voz hablando de la necesidad de más autorizaciones para las asociaciones de nueva creación:

„No se concede a cualquiera el poder constituir una sociedad, un colegio u otra corporación semejante, porque esto se halla regulado por leyes, senadoconsultos y constituciones imperiales. En muy pocos casos se han permitido tales corporaciones; por ejemplo se permitió formar corporación a los socios arrendatarios de la recaudación de las contribuciones públicas o de las minas de oro o plata, o de las salinas. También existen en Roma ciertos colegios, cuya corporación fue confirmada por senadoconsultos y constituciones imperiales, como el de los panaderos y otros varios, y los de los navieros que también existen en las provincias. Los que pueden constituirse como colegio, sociedad o cualquier otra corporación, tienen, como si fueran una ciudad, bienes comunes, caja común y un apoderado o síndico, por medio de quien, como en una ciudad, se trate y haga lo que debe tratarse y hacerse en común",

„Si hay asociaciones ilícitas, deben disolverse como ordenan los mandatos, constituciones imperiales y senadoconsultos, pero, al disolverse, se les permite dividir el dinero común y repartirlo entre los socios. En suma: si se hace una asociación o corporación cualquiera sin ajustarse a la autoridad del senadoconsulto o del príncipe, las reuniones son contra el senadoconsulto y las constituciones"9.

En la época imperial las asociaciones quedaron divididas en dos categorías: los collegia licita y los collegia illicita. Tácito en Annales menciona los acontecimientos ocurridos en la colonia de Nuceria (cerca de actual Salerno) que como consecuencia el senado prohibía sus reuniones y había disuelto los colegios constituidos ilegalmente:

„El caso es que muchos de los de Nuocera fueron llevados a la Ciudad con el cuerpo lleno de mutilaciones, en tanto que la mayoría lloraba la muerte de hijos o padres. El príncipe delegó en el senado el juicio sobre el asunto, y el senado en los cónsules; pero el tema volvió de nuevo al senado y se prohibió por diez años a los de Pompeya aquella clase de reuniones, y se disolvieron los colegios que habían constituido ilegalmente" 10 .

El término illicitus se aplicaba a las asociaciones constituidas sin autorización y aquellas que, aún habiendo sido autorizadas, pudieran tener algún peligro implícito. Se tenía en cuenta también la frecuencia de las reuniones. Así, los

${ }^{8}$ Dig. $3,4,1$.

${ }^{9}$ Dig. $47,22,3,1$.

10 Tacitus, Anales XIV 17, en: Cayo Cornelio Tácito, Anales. Obra completa, trad. C. de Colona, Madrid 1986, 156. 
tenuiores, p. ej. mantenían su situación de preferencia siempre y cuando sólo se reunieran una vez al mes, ya que una mayor frecuencia de sus reuniones podría llevarles a ser collegia illicita:

„Se ordena a los gobernadores provinciales, en algunos mandatos imperiales, que no toleren la existencia de asociaciones de cofrades, ni que los militares tengan asociaciones en sus campamentos. Sin embargo, está permitido a la gente humilde el aportar cotizaciones mensuales, con tal de que no se reúnan más de una vez cada mes, a fin de que no formen con tal pretexto una asociación ilícita" ${ }^{11}$.

La organización asociativa interna se regía por los estatutos de los cuales habla la ley de las XII Tablas ${ }^{12}$. El estatuto, llamado lex collegii constituía la base de la organización asociativa. Por eso, los que entraban en la asociación tenían que leer atentamente los estatutos ${ }^{13}$. Parece que casi todas las personas tenían la posibilidad de reunirse en grupos de amigos, parientes, vecinos o socios laborales, elaborar un estatuto, buscar un lugar de reunión y autodeclararse como una asociación. El grupo contaba generalmente diez a treinta o cuarenta miembros. En familias muy extensas los señores promovían la formación de una asociación y ofrecían un lugar de reunión, como es el caso de la sociedad de entierros, que se reunían en la casa de Sergia Paulina en Roma $^{14}$. La familia podía ser también la base de una asociación de culto, como Pompeia Agrippinilla, que fundó un thiasos dionisíaco en Túsculo al principios del Siglo II d. C. La jerarquía de los cargos en la asociación cultual reproducía la jerarquía de la familia ${ }^{15}$.

Las asociaciones tenían sus cargos, con títulos imitados de los cargos municipales. Los collegia de Roma contaban generalmente con un grupo de presidentes denominados magistri. Otro cargo de mucha importancia era el tesorero. Corría a su cargo la contabilidad del haber y el debe y el pago de los gastos regulares de banquetes, fiestas, ritos religiosos, homenajes a los patrocinadores, y en muchos casos los funerales de sus socios. Cada asociación tenía su caja. El dinero que contenía la caja tenía principalmente dos fuentes. Primero, las contribuciones de los miembros, y segundo los donativos de los ricos patronos ${ }^{16}$.

Meeks afirma que en el periodo imperial en Tesalónica en la calle 18 se reunían los constructores y los carpinteros, los tapiceros y los alfombreros, los porteros y los tintoreros de púrpura. El fin prioritario de las reuniones consistía en la participación en una comida un poco mejor que la habitual, beber el

11 Dig. 47, 22, 1.

12 Cfr. Dig. 47, 22, 4.

13 Cfr. CIL XIV 2112, I, 18-19: „tu qui novos in hoc collegio intrare voles, prius legem perlege et sic intra, et postmodum quaeraris aut heredi tuo controversiam relinquas".

${ }^{14}$ Cfr. CIL I 69148: „Collegium quod est in domu Sergiae Paullinae”.

15 Cfr. W.A. Meeks, Los primeros cristianos urbanos, Salamanca 1988, 59.

${ }^{16}$ Cfr. De Robertis, Il fenomeno associativo, p. 72-73. 
mejor vino, celebrar el onomástico del fundador o patrocinador, o la fiesta de Poseidón o de Hermes o de Isis ${ }^{17}$.

2. Asociaciones religiosas. La religión fue uno de los motivos fundamentales para formar asociaciones entre los romanos. Los colegios religiosos tienen un origen remoto, siendo probable que los Lupercales, sodales Titi y fratres Arvales, fueran producto de la iniciativa privada, en época precívica ${ }^{18}$. Los colegios religiosos se dividieron en oficiales o semi-oficiales y privados. Los primeros estaban encargados del culto público por el Estado, como es el caso de los sodales Augustales. Los colegios religiosos privados fueron aquellos que libremente rindieron culto a una divinidad por ellos escogida. Estos colegios existían desde la época republicana y aumentaron en la época Imperial. También se consideraban colegios religiosos privados a los formados por grupos que honraban a los emperadores vivos o muertos o a los Lares de una ciudad o de una persona importante y estaban formados generalmente por gente humilde, clientes y esclavos ${ }^{19}$.

En Italia había ejemplos abundantes de colegios religiosos privados. Sus miembros no eran sacerdotes, como los del culto oficial, sino simplemente cultores de una divinidad, que asistían a los ritos y sacrificios, presididos por los magistri, y tenían sus templos para realizar los cultos (sacella). En España, concretamente en Carthago Nova, hay dos ejemplos de este tipo de colegios. Una inscripción aunque no nos da el nombre de la asociación, nos ofrece una lista de los magistri de un sacellum dedicado a una divinidad. Entre los magistri hay libres, libertos y esclavos en la siguiente proporción: dos libres:

„C(aius) Poplici(us), L(ucius) Cerui(us); cinco libertos: M. Caeici(us), G(aii) 1(ibertus), L. Talepi(us), A(uli) 1(ibertus), Cn. Tongili(us), Pyl(ades?), L. Paqui(us), Lon(g)i? 1(ibertus), Q. Verati(us) Cis(sus?); dos esclavos: Pil(emo) Pontili(us), M(arci) C(ai) s(ervuus), Q. Claudi(us) Pos(por?), C(ai) s(ervuus)"20.

La segunda inscripción de Carthago Nova también contiene la lista de los magistri de un sacellum. Los magistri son: cinco libertos:

„M. puupius, M(arci) 1(ibertus), Sex. Luucius, Sex(ti) 1(ibertus), M. Prosius, M(arci) l(ibertus), N. Titius, L(uci) l(ibertus), C. Vereius, M(arci) l(ibertus); y cuatro esclavos: Antioc(hus), Bruti e(t) Terenti C. s(ervuus), Pilemo Aledi, L(uci) s(ervuus), Alex(ander) Titini L(uci) s(ervuus), Acerd(o) Sapo(nii) $\mathrm{M}\left(\right.$ arci) s(ervuus) ${ }^{\prime 21}$.

${ }^{17}$ Cfr. Meeks, Los primeros cristianos, p. 60.

18 Cfr. De Robertis, Il fenomeno associativo, p. 22.

19 Cfr. J. M. Santero Santurino, Asociaciones populares en Hispania romana, Salamanca $1978,14$.

${ }^{20}$ CIL II 3433.

21 CIL II 3434. 
Otro tipo de colegios religiosos eran los dedicados a rendir el culto al emperador vivo o muerto. Este culto estaba organizado oficialmente en todo el Imperio. Cada ciudad tenía sus sacerdotes oficiales. Pero también hubo colegios privados cuyo objetivo era rendir culto al emperador divinizado. Este tipo de colegio nos encontramos en Hispania, que se titula collegium divi Augusti ${ }^{22}$, cuya finalidad parece ser simplemente religiosa, es decir, honorar a Augusto divinizado. A. D'Ors dice que se trata de un colegio con fines cultuales ${ }^{23}$.

Un tipo peculiar de colegios religiosos era el de los cultores Larum. Desde época republicana había asociaciones cuya finalidad era rendir culto a los Lares en unas edículas que se ponían en los cruces de las vías ${ }^{24}$. Estos tipos de asociaciones estaban formados generalmente por esclavos y libertos, que podían ser pertenecientes a una familia, o bien públicos. En el primer caso se trata de colegios domésticos, y su finalidad es honrar a los Lares de esa familia. En el segundo caso se trata de familias públicas de esclavos y libertos que honran a los Lares públicos. Este tipo de cultores Larum domésticos es muy frecuente en la epigrafía romana donde encontramos p. ej. „Cultores Larum Sex. Antoni Mansueti”,25, „Collegium Larum in domo Iuliana”26, „Collegium Larum Marcellini",27.

La mentalidad de los romanos se mostraba abierta ante la novedad que ofrecían algunos cultos extranjeros, aceptándolos como sucedía con la religión judía a quien Julio César concedió el derecho de reunión y de formación de asociaciones $^{28}$. Durante el Imperio la afluencia de cultos extranjeros continúa, aumentando tanto en la variedad como en el número de sus adeptos. El carácter voluntario, el misterio y la capacidad para conmover los sentimientos personales, el componente espectacular de sus ritos, fiestas, procesiones son los factores que contribuyeron a la captación de nuevos cultores. La proximidad a lo humano que tienen los dioses orientales - sufren, mueren y resucitan como Osiris, Atis, Adonis, proporcionan fuertes emociones ausentes en la serenidad de los dioses romanos ${ }^{29}$.

De la ciudad de Napoca en Dacia - 235 d. C. - nos ha llegado la lista de miembros de un colegio báquico llamado asianores ${ }^{30}$. En la primera línea aparece el nombre Germano, presidente spriarcha de la asociación. Trajano

22 Cfr. CIL II 2573.

23 Cfr. A. D’Ors, Epigrafía jurídica de la España romana, Madrid 1953, 384.

${ }^{24}$ Cfr. De Robertis, Il fenomeno associativo, p. 85.

25 CIL XII 2677.

26 CIL XIII 1747.

27 CIL IX 2481.

${ }^{28}$ Cfr. M. Simón, Verus Israel. Étude sur les relations entre chrétiens et juifs dans l'Empire romain (135-425), Paris 1964, 125-127.

${ }^{29}$ Cfr. F. Cumont, Las religiones orientales y el paganismo romano, Paris 1966, 38.

${ }^{30}$ Cfr. CIL III 870: „Severo et Quintiano cos(...) nomina asianorum”. 
en su política de colonización de la Dacia trasladó a gente de todo el imperio a esta provincia y ellos debieron proceder de Asia. Pero no fueron los únicos en la ciudad porque ya existió un colegio formado también por inmigrantes galaecios $^{31}$. Dos teónimos Atis y Cibeles forman parte de una pareja divina de las varias que nos ofrecen las religiones orientales. Atis es el esposo de Cibeles, diosa de la tierra, madre de todas las cosas y señora de las fieras del bosque. Durante el Imperio sus fiestas se siguen celebrando de manera muy solemne en Roma. Su culto se extendió por todo el imperio: Hispania, Britania, países danubianos, África y sobre todo Galia ${ }^{32}$.

Los colegios religiosos disponían de un lugar para su culto, el templo. Había colegios que se reunían en templos públicos, pero otros tenían su propio templo para el culto y, dentro de él, un lugar de reunión o schola, que era una sala de reuniones y conversaciones, con bancos colocados en semicírculo, de forma que los auditores podían celebrar sus reuniones de manera más cómo$\mathrm{da}^{33}$. En estos templos o scholae, durante las reuniones de los colegios, se proponían las actividades de la asociación, como las dedicaciones ${ }^{34}$. En las reuniones religiosas de los colegios se efectuaban los ritos correspondientes al culto de que se tratara. Para estas ceremonias, el colegio estaba organizado jerárquicamente. El que dirigía la ceremonia era el presidente del colegio (magister). Las funciones de otros magistri de colegios religiosos no eran solamente de dirigir las ceremonias, sino además llevar todos los asuntos relacionados con la organización del colegio y cuidar del sacellum, es decir templo donde se celebraban las ceremonias. Una de las inscripciones nos dice que estos magistri se preocupaban de hacer parte del sacellum: „magistri pilas III et fundamentum ex caemento faciendum coerauere" 35 .

Normalmente el presidente del colegio, magister quinquenalis, llamado así por ser elegido para cinco años, es el que preside las ceremonias religiosas, a parte de regir todos los asuntos del colegio. Esto es lo que dice el reglamento de los cultores Dianae et Antinoi de Lanuvium:

„Item placuit, ut quinquennalis sui cuiusque temporis diebus solemnibus ture et vino supplicet et ceteris officiis albatus fungatur" ${ }^{36}$.

En los asuntos financieros de los colegios religiosos fue normalmente el magister quien decidía, pero a veces el colegio en conjunto tomaba decisiones, como

31 Cfr. CIL III 1394: „Herculi invicto p(ost) r(editum) inperatoris col(legium) (G)alatorum (T)i Iulius Marcellinus d(onum) d(edit) d(edicavit)".

32 Cfr. Cumont, Las religiones orientales, p. 56.

${ }^{33}$ Cfr. Santero Santurino, Asociaciones populares, p. 58.

${ }^{34}$ Cfr. CIL II 5811: „M(arcus) Sempronius L(uci) f(ilius) Cep(h)alo Cornelianus”.

35 CIL II 3434.

36 CIL XIV 2112. Un caso particular es el de Aulus Publicius Germanus, que, por una parte, es sacerdos familiae publicae de Corduba, y, además, magister II del colegio; cfr. CIL II 2229. 
es el caso de los piscatores et propolae de Carthago Nova, que votaron la aprobación para erigir un monumento ${ }^{37}$.

3. Asociaciones funerarias. Las restricciones en materia asociativa dadas por la lex Iulia, inauguraron un sistema de control estatal sobre los colegios para toda la época imperial. Desde la promulgación de la ley, todo colegio debía obtener una autorización para constituirse. Este es el caso de los collegia tenuiorum, autorizados por un senadoconsulto de mediados del siglo I d. C. ${ }^{38}$. Tenuiores eran gentes de escasos recursos económicos que se asociaban bajo la advocación de una divinidad para cubrir sus necesidades de funerales y enterramiento. Estos colegia tenuiorum recibieron en la época de Claudio una autorización que aparece en el Digesto ${ }^{39}$. Esta noticia de Marciano está confirmada por una inscripción que contiene los estatutos del collegium salutare Dianae et Antinoi ${ }^{40}$.

A partir de la entrada en vigor del senadoconsulto sobre tenuiores, los colegios funerarios se extendieron por todas partes del Imperio. La abundancia de este tipo de colegios se explica por la importancia que daban los romanos a la sepultura. Para ellos continuaba la vida en la tumba, y los difuntos sólo encontraban reposo si tenían una sepultura digna. Por eso, las atenciones debidas a los muertos resultaban bastante costosas. La enorme masa de gentes carecía de los recursos económicos y tenía que ingeniárselas para cubrir estas necesidades funerarias. Así, los clientes, libertos y esclavos de las familias ricas, que no podían soportar los gastos de una tumba, se agregaban a las grandes sepulturas y mausoleos de sus patronos. Sin embargo, cuando los patronos no eran ricos para cubrir estas necesidades, muchos tenuiores quedaban sin sepultura, y esto fue frecuente en la época republicana y comienzos del Imperio, en que existían grandes fosas públicas donde se arrojaban los cadáveres de los pobres ${ }^{41}$. Para solucionar este problema, a comienzos del Imperio, surgieron los llamados socii columbariorum, que no eran colegios en el sentido estricto, sino que en realidad eran ,sociedades por acciones, que se limitaban a tener un fondo, formado con las cotizaciones de los socios, con el que se cubrían los gastos ocasionados a la muerte de uno de ellos, garantizándose un nicho en los grandes columbarios que construía la sociedad" 42 .

37 Cfr. CIL II 5929: „, de pecunia sua faciendum curaverunt idemque probaverunt”.

38 Cfr. Santero Santurino, Asociaciones populares, p. 63.

39 Cfr. Dig. 47, 22, 1.

40 Cfr. CIL XIV 2112: „Caput ex s(enatus) c(onsulto) p(opuli) r(omani). Quibus coire convenire collegiumque habere liceat. Qui stipem menstruam conferre volent in funera, in it collegium coeant, neq(ue) sub specie eius collegii nisi semel in mense coeant conferendi causa unde defuncti sepeliantur".

${ }^{41}$ Cfr. Santero Santurino, Asociaciones populares, p. 67-68.

${ }^{42}$ Ibidem, p. 68. Este tipo de sociedades sólo existieron en Roma, y, además, duraron muy poco, porque desde mediados del siglo I d. C. apaecen casi en todo Imperio verdaderos colegios 
Las asociaciones, que Marciano ${ }^{43}$ llama collegia tenuiorum, son también conocidas con el nombre de collegia funeraticia. Entre ellas se encuentran sobre todo las denominadas collegia salutaria y las de cultores deorum. Estas últimas tenían finalidad principalmente funeraria, como se deduce de la inscripción que contiene la lex del collegium salutare de cultores Dianae et Antinoi de Lanuvium ${ }^{44}$.

Todos estos colegios funerarios tenían como finalidad fundamental proporcionar a sus miembros un enterramiento digno, como señalan los estatutos del colegio de Lanuvium: „bene atque industriae contraxerimus, ut exitu defunctorum honeste prosequamur" $" 45$. Los asociados pagaban, en primer lugar, un derecho de entrada, que, en el caso del colegio de Lanuvium consistía en 100 sestercios, y después una cotización mensual de 5 ases. Al morir uno de sus miembros, el colegio de cultores Dianae et Antinoi pagaba al heredero del difunto la cantidad de 300 sestercios para que se le construyera una tumba y se le hicieran los honores fúnebres apropiados. Otros colegios, sin embargo, disponían de sus propios lugares de enterramiento. Si el difunto no tenía herederos, el colegio se encargaba del enterramiento y funerales ${ }^{46}$.

Los miembros de los colegios funerarios pertenecían, como dice De Robertis, a las clases más bajas de la población ${ }^{47}$. Entre las puertas Salaria y Pinciana de la ciudad de Roma se encontró una inscripción encargada por unos soci monumenti ${ }^{48}$. Esta asociación tenía en el año 9 d. C. veinticinco miembros, $\operatorname{soci}^{49}$. En el cementerio de Calixto de Roma, una tabla de columbario recoge los nombres, incompletos, de tres varones probablemente decuriones ${ }^{50}$.

Un dato de mucho interés nos ofrece la inscripción del collegium Iovis Cerneni de Alburnus Maior en Dacia, sobre tres tabellae ceratae. Se trata de la disolución de un colegio funerario de esclavos por falta de miembros y de organización. El Magister del colegio, junto con dos esclavos quaestores, le-

funerarios, que fueron autorizados por el senadoconsulto de época de Claudio, resolviéndo el problema de los tenuiores que no podían costearse privadamente una sepultura digna; $\mathrm{cfr}$. ibidem.

43 Cfr. Dig. 47, 22, 1.

${ }^{44}$ Cfr. CIL XIV 2112. Otras inscripciones como la del collegium Aesculapi et Hygiae de Roma (CIL VI 10234), de los cultores collegi Silvani de Philippo (CIL III 633), del collegium Iovis Cerneni de Dacia (CIL III 924-927) y del collegium Siluani de Lucania (CIL X 444) tienen importancia en este sentido.

45 CIL XIV 2112.

${ }^{46}$ Cfr. Santero Santurino, Asociaciones populares, p. 68-69.

${ }^{47}$ Cfr. De Robertis, Il fenomeno associativo, p. 24: „Di origine ancor più recente sono y collegia tenuiorum: essi avevano lo scopo di permettere ai soci, appartenenti alle classi più basse della popolazione, le pratiche del culto divino, in ordine sia agli dei Superi che ai Mani, assicurando agli aderenti y funerali e le oronanze di rito".

48 Cfr. CIL VI, 34004: „L. Munio Gnomone Q Volumnio Amphione qui recte soci monumenti sunt".

49 Cfr. Dig. 17, 2, 70.

50 Cfr. CIL VI 34004a. 
vantan un acta para hacer saber que, de 54 miembros, el colegio ha quedado reducido a 17, que Iulius, otro magister colegii no ha aparecido por el colegio desde el día de su elección, que se han rendido cuentas a los miembros presentes, devolviéndoles el dinero que había hasta vaciar la caja. Por todo ello se ha disuelto el colegio. El acta se firmó el día 5 de los Idus de Febrero (año 167 d.C. $)^{51}$.

Los esclavos y libertos, que poseían en abundancia las familias ricas, solían formar uno o varios colegios funerarios con el fin de asegurarse una sepultura en un lugar común. Estas asociaciones denominadas collegia domestica, hay que suponer que su funcionamiento era similar al de los colegios funerarios siguiendo un sistema de pago de cuotas mensuales para formar un fondo común. Colegios formados por esclavos y libertos de familias ricas fueron los que se denominaban cultores Larum, que tenían un marcado carácter religioso adorando los Lares de una familia ${ }^{52}$.

Ahora bien, puesto que existieron colegios funerarios mixtos compuestos por esclavos y libertos, podríamos preguntarnos sobre la existencia de colegios formados exclusivamente por esclavos. De Lucus Augusti viene una inscripción funeraria que está dedicada a una esclava decoradora, de origen griego, Philtate, por sus conserui, pertenecientes a la casa de Augustus Aurinus ${ }^{53}$. Según J. Mangas se trata de un colegio funerario formado exclusivamente por esclavos de una familia, es decir un colegio funerario doméstico de escla$\operatorname{vos}^{54}$. En Caldas de Reyes (Pontevedra) se encontró una inscripción en forma de lista de nombres de personas donde aparecen tres esclavos de un centurión: Sabinus de 20 años, Secundio de 22 y Lentinus de 20. Todos ellos aparecen enterrados juntos ${ }^{55}$. Mangas sospecha en esta inscripción la presencia de un colegio, que en este caso sería exclusivamente de esclavos ${ }^{56}$. Finalmente, en una inscripción que proviene de Corduba aparece el nombre de Aulus Publicius Germanus que era „sacerdos perpetuus familiae publicae” y „magister II” del colegio ${ }^{57}$. Esta asociación, por tanto, ha de ser considerada como religioso -

51 Cfr. CIL III 924-927.

52 Cfr. CIL II 174: „Aesculapio aug(usto) sacrum cultores Larum Maliae Malioli M(arcus) Cossutius Macrinus donavit"; cfr. E.M. Steuermann, Colegios y familias de esclavos en la época imperial, en: „Vestnik Drevnej Istorii” 33 (1950) 71-85.

${ }^{53}$ Cfr. „Ephemeris Epigraphica” 8 (1892) n. 311: „D(is) M(anibus) Philtates ornatricis C... caelniteae conservo domo Augusti Aurini s(ervae) conservi eius".

${ }^{54}$ Cfr. J. Mangas Manjarres, Esclavos y libertos en la España romana, Salamanca 1971, 119.

55 Cfr. Inscriptiones Romanas de Galicia (= IRGalicia), III, Santiago de Compostela 1968, 38: „Sabinus an(norum) XX Secundio an(norum) XXII Lentinus an(norum) XX M(arci) Audasi c(enturionis) leg(ionis) X gem(inae) ser(vi) h(ic) S(iti) s(unt)".

${ }^{56}$ Cfr. Mangas Manjarres, Esclavos y libertos, p. 118-119.

57 Cfr. CIL II 2229: „A(ulo) Publicio (ge)rmano scerdoti (fa)miliae publicae c(olonorum) c(oloniae) p(atriciae) perpetuo mag(istro) II (tr)ophimus c(olonorum) c(oloniae) p(atriciae)s ser(vus) (e)mptu germanianus D(eo) s(uo) d(edit)". 
funeraria, con su sacerdote para las ceremonias religiosas, y su magister como todo colegio ${ }^{58}$.

\section{LAS ASOCIACIONES Y LOS CRISTIANOS}

Los colegios cristianos aparecen como las asociaciones de carácter esencialmente religioso. En general, las asociaciones cristianas no tomaban los nombres tradicionales de las asociaciones romanas como: collegium, sodalicium, sodalitas, etc., sino ecclesia fratrum, fratres, fraternitas, sodales fratres,

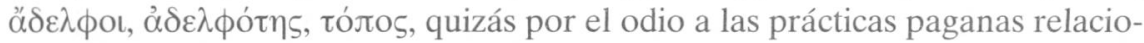
nadas con aquellos nombres. El Estado, por el contrario, le designa siempre

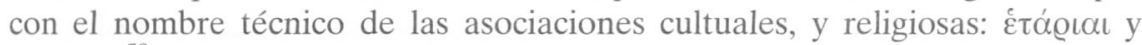

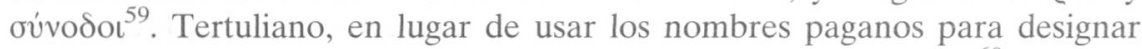
una asociación, utiliza el vocabulario intermedio: coetus y conticula ${ }^{60}$. Eusebio habla de seguidores, $(\theta$ เ $\alpha \omega \dot{\tau} \tau \alpha))^{61}$. Los mismos cristianos, para denominar a los socios de los collegia tenuiorum, utilizaron la palabra „cultores”.

1. La legalidad del cristianismo. Uno de los principios fundamentales de los antiguos era que el hombre tenía ciertos deberes respecto a la divinidad. Un romano debía rendir culto a los dioses de Roma, un ateniense a los de Atenas etc. La religión era, pues, esencialmente nacional. Este principio, sin embargo, no excluía el ejercicio de un culto extranjero, siempre que su práctica estuviera limitada únicamente a los extranjeros allí domiciliados, quienes, separados del culto nacional de su país, no podrían tener religión alguna si no se les permitiera ejercer la propia. Este contacto local no suponía fusión de las religiones, tampoco facilitaba el franqueamiento de las barreras que las separaban. Así pues, el exclusivismo absoluto de las religiones judía y cristiana no se fundaba en el sentimiento patriótico, sino doctrinal. El Dios de Israel, el mismo de los

${ }^{58}$ Cfr. Santero Santurino, Asociaciones populares, p. 87.

59 Cfr. Eusebius, Historia Ecclesiastica (= HE) VII 10, 11, trad. A. Velasco-Delgado, Madrid 1973, 178: „Es el sitio que escogí, por mandato de nuestros augustos, y de ninguna manera os estará permitido, ni a vosotros ni a ningún otro, hacer reuniones ( $\dot{\eta}$ oúvodos) o entrar en los llamados cementerios".

${ }^{60}$ Cfr. Tertullianus, Apologeticus 2, 6 et 38, 3, CCL 1, 88 et 149; Adversus Marcionem II 12, 2 , CCL 1, 489; Adversus Valentinianos 13, 2, CCL 2, 764; De carne Christi 5, 10, CCL 2, 882; Scorpiace 15, 1, CCL 2, 1096.

${ }^{61}$ Cfr. Eusebius, HE I 3, 19, trad. Velasco-Delgado, p. 17: „Una prueba sólida y patente de esta unción incorporal y divina es que, de todos los hombres de su tiempo y de los que luego han seguido hasta hoy, únicamente Él, entre todos y en el mundo entero, ha sido llamado y proclamado Cristo; solamente a Él reconocen bajo este nombre, dan testimonio de Él y le recuerdan todos, lo mismo entre griegos que entre bárbaros; y hasta hoy todavía sus seguidores, repartidos por toda la tierra habitada, siguen dándole honores de rey". 
cristianos, no era un dios local, propio de un país o de un pueblo determinado, uno de tantos dioses, sino un único Dios, el Dios de todas las naciones y razas, creador del mundo, legislador y juez de la humanidad. Los demás dioses „eran dioses falsos, hombres divinizados, demonios, ídolos. Fuera del culto del Dios verdadero, del Dios de Israel y de los cristianos, cualquier otro era impiedad; las religiones de las ciudades, de las naciones, del imperio, falsas, impías, errores diabólicos contra los cuales todo hombre tenía el derecho y el deber de protestar" 62 .

1.1. La distinción entre los cristianos y los judíos. El judaísmo, durante la época de Vespasiano, gozaba del privilegio de ser una religión permitida. Vespasiano comprendió que ese culto significaba algo más que una cuestión de nacionalidad y se limitó a transferir al templo de Júpiter Capitolino el tributo que los hijos de Israel habían pagado hasta entonces a Jahvé y a su santuario. Los gobernadores romanos rehuían intervenir en las querellas contra los cristianos porque les costaba mucho distinguir los cristianos de los judíos y comprender la causa de la antipatía de éstos contra aquellos ${ }^{63}$. Resulta, pues, evidente que los judíos no querían que los cristianos se aprovecharan de sus privilegios. Empezaron las denuncias a las autoridades, y entonces comenzó para el cristianismo la era de las proscripciones. San Pedro en su primera carta hace una recomendación: „Que ninguno de vosotros tenga que sufrir por asesino o ladrón, por malhechor o por meterse en asuntos ajenos. Pero si es por ser cristiano, que no se avergüence, sino que glorifique a Dios por llevar ese nombre" (1Pe 4, 15-16).

Los sufrimientos de que aquí habla San Pedro son los castigos impuestos por los tribunales ordinarios encargados de la represión de los crímenes de robo, asesinato, etc. El Apóstol se expresaba así porque los referidos tribunales habían empezado a entender ya el delito de ser cristiano. Los cristianos eran denunciados, inquiridos, juzgados y condenados por el solo hecho de ser cristianos, y aunque la opinión pública les imputaba toda clase de crímenes, nunca se dio el caso de que se les condenara por magos o por sacrílegos. Tertuliano declara expresamente que aquellos supuestos delitos no aparecen en las sentencias:

${ }^{62}$ L. Duchesne, Histoire ancienne de l'Église, I, Paris 1906, 102: „Les autres deux n'étaient que de faux dieux, des hommes divinisés, des démons, des idoles; ils en comptaient pas. En dehors du sien, tont culte était une impiété; les religions des cités, des nations, de l'empire, n'étaient que de prétendues religions, des erreurs diaboliques contre les quelles tont homme ovait le droit et le devoir de protester".

${ }^{63}$ Buena prueba de esto nos ofrecen las perplejidades de Pilatos, la negativa de Galión, proconsul de Acaya, a escuchar las quejas que los judíos de Corinto presentaron contra San Pablo, y la indiferencia con que Félix y Festo acogieron las denuncias del sumo sacerdote contra el mismo Apóstol. 
"Yuestras sentencias sólo constan la confesión del nombre cristiano; ninguna especie de crimen aparece en ellas, pues el único es aquel nombre" ${ }^{\prime 64}$.

Luego, copiando la sentencia añade:

„¿Qué es, en fin, lo que leéis en vuestras tablillas? Que el reo es cristiano. ¿Por qué no añadís, y homicida?" ${ }^{65}$.

Después de Trajano algunos emperadores se mostraron más dispuestos a mitigar las consecuencias de la ley. Adriano escribió en este sentido a varios gobernadores, entre otros a C. Minucio Fondano, procónsul de Asia:

"«Por consiguiente, si los habitantes de una provincia pueden sostener con firmeza y a las claras esta demanda contra los cristianos, de tal modo que les sea posible responder ante un tribunal, a este solo procedimiento habrán de atenerse, y no a meras peticiones y gritos. Efectivamente, es mucho mejor que, si alguno quiere hacer una acusación, tú mismo examines el asunto. Por lo tanto, si alguno los acusa y prueba que han cometido algún delito contra las leyes, dictamina tú según la gravedad de la falta. Pero si - ¡Por Hércules! - alguien presenta el asunto por calumniar, decide acerca de esta atrocidad y cuide de castigarla adecuadamente». Tal es el rescripto de Adriano"66.

El apologista Melitón intentaba disuadir a Marco Aurelio de su empeño en perseguir a los cristianos, alegando los rescriptos de Adriano y otros que Antonio Pío ha dirigido a las ciudades de Larisa, Tesalónica, Atenas y a la junta de Acaya:

„Más si alguien persistiera en llevar al tribunal a alguno de ellos (cristianos) por ser tal, quede el acusado libre de cargos, aun cuando, aparezca evidente que es cristiano; en cambio, el acusador quedará sujeto a castigo"67.

Desde el momento en que las autoridades romanas establecieron oficialmente la distinción entre judíos y cristianos, éstos últimos se encontraron en la situación de ocultar sus creencias y su existencia corporativa, para evitar el rigor de las leyes contra las asociaciones no autorizadas, entre las cuales se encontraban las cristianas. Plinio en la carta a Trajano habla de la multitud de cristianos de todas edades, sexos, que se reúnen para celebrar sus ceremonias. Plinio, sin embargo, no tenía ninguna necesidad de instrucciones para prohibir aquellas asambleas $^{68}$.

${ }^{64}$ Tertullianus, Ad nationes 3, 2, CCL 1, 13.

65 Idem, Apologeticus 2, 20, CCL 1, 91.

${ }^{66}$ Eusebius, HE IV 9, 2-3, trad. Velasco-Delgado, p. 172.

${ }^{67}$ Ibidem IV 13, 7, 178. Esta actitud incomprensible bajo Antonio Pío y Marco Aurelio, bastaría para hacer sospechar de la autenticidad.

${ }^{68}$ Cfr. Plinius, Epistolae X 96, trad. A. Fontán - A. Moure - A. Casas, Madrid 1995, 145: „Multi enim omnis aetatis, omnis ordinis, utriusque sexus etiam, uocantur in periculum et uoca- 
1.2. La propiedad corporativa de la iglesia cristiana. La comunidad cristiana, desde sus comienzos, poseía sus recursos pecuniarios, una caja común, y un siglo después de Trajano eran dueños de algunos inmuebles, templos y cementerios, que figurarían en los registros como propiedades de alguna persona individual. Los cristianos no podían invocar, para excluir de sus cementerios a quien al morir no hubiese pertenecido a su grupo, la cláusula ad religionem pertinentes meam, con que el propietario o fundador de algún sepulcro designaba las personas que en él podían ser inhumadas, puesto que siendo el cristianismo religio illicita estaba excluido del favor de las leyes ${ }^{69}$.

a. La te oría de Duchesne. Trajano consecuente con su principio de que toda asociación era peligrosa, prefería exponer las ciudades a los riesgos de un incendio antes que permitir que se formaran cuerpos de bomberos. Ahora bien, ¿a qué tipo de astucia tendrían que recurrir las comunidades cristianas para disimular su vida social, tan corporativa? La Iglesia, como ya hemos dicho, desde el principio poseía recursos pecuniarios, una caja común. Desde los comienzos del siglo III, las iglesias eran propietarias como entidades morales al amparo de la legislación vigente sobre colegios funerarios. Se permitía a los pobres y demás gente asociarse con el fin de prepararse una sepultura digna. Esas asociaciones podían señalar cuotas mensuales a sus miembros, poseer y celebrar asambleas de carácter religioso y nombrar un actor que las representara jurídicamente. Teniendo en cuenta todo esto, Duchesne hace una pregunta: „¿Por qué, pues, las comunidades cristianas habían de estar excluidas de ese derecho, toda vez que ellas, más que ninguna otra asociación, ponían especial cuidado en organizar y velar por sus cementerios, y presentándose como colegios funerarios se colocaban al abrigo de la ley?"70. Según Duchesne hay muchas razones; pero la más importante era la aversión que tales colegios inspiraban. Dice que: „los emperadores del tercer siglo observaron respecto de la Iglesia una actitud bien definida, pues o la persiguieron resueltamente, o la toleraron en igual forma, sin que para ellos fuera jamás una sociedad desconocida, porque los lugares en que se reunían los cristianos, los cementerios, los nombres y domicilios de los superiores, no es posible suponer que los ignorasen los magistrados ni la misma administración imperial. En efecto, apenas estallaba una persecución las primeras víctimas, si no escapaban o se ocultaba a tiempo, eran los obispos, y los lugares del culto y demás bienes

buntur. Neque ciuitates tantum sed uicus etiam atque agros superstitionis istius contagio peruagata est".

${ }^{69}$ Cfr. G.B. De Rossi, Roma sotterranea, Roma 1857, 102.

70 Duchesne, Histoire ancienne de l'Église, 384: „Pourquoi les groupes chrétiens n'auraient-ils pas été admis à jouir de ces facilités? Pourquoi, eux qui avaient un tel soin de leurs sépultures, n'auraient-ils pas présenté leurs communautés comme des collèges funéraires, les plaçant ainsi à l'abri de la loi?". 
eclesiásticos los primeros confiscados. Después de la persecución, el obispo era quien reclamaba y a quien se autorizaba para exigir la devolución de esos bienes" ${ }^{\text {" }}$. Tertuliano, comparando las asociaciones paganas con las asociaciones cristianas, pone de relieve los rasgos que les distinguían:

„Mas puede suceder que se nos mire como a hermanos menos legítimos por no haber tragedia alguna que declame acerca de nuestra fraternidad o bien porque usamos como hermanos de nuestros bienes familiares, los que entre vosotros rompen la fraternidad. Por donde los que convivimos compenetrados en espíritu y en alma, no dudamos en comunicar con otros nuestras cosas. Todo entre nosotros es común, menos las mujeres. En este punto rompemos el consorcio, en el único en que los demás hombres practican el consorcio, pues no sólo usurpan las mujeres de sus amigos, siguiendo en esto, creo, la doctrina de los mayores y de los más grandes sabios: del griego Sócrates y del romano Catón, quienes entregaron sus mujeres a sus amigos, aun cuando las desposaron, sin duda, para que les diesen hijos, aunque fuesen de otros, no sé si contra la voluntad de ellas"72.

San Cipriano nos cuenta, que un obispo de España fue condenado por las autoridades eclesiásticas por el hecho de haberse inscrito en una asociación funeraria y hecho enterrar en la misma a sus hijos:

„Marcial, además de haber asistido a menudo a convites impuros y vergonzosos de los gentiles en una asociación y de haber enterrado a sus hijos en la misma asociación, con rito gentil en sepulcros profanos y entre los paganos ha confesado que en sesión pública ante el procurador ducenario obedeció a las órdenes de la idolatría y renegó de Cristo" ${ }^{\text {73 }}$.

Hay que añadir también, que las leyes sobre esas corporaciones suponían, como condición fundamental, que de ningún modo se abusara el senado consulto que prohibía las asociaciones ilícitas, y entre ellas la religión cristiana.

b. La teoría de De Rossi. Había autores, especialmente en el siglo XIX, que decían que los primeros grupos cristianos imitaron el modelo de las asociaciones voluntarias, sobre todo el de los collegia tenuiorum o sociedades funerarias ${ }^{74}$. Este modelo no podría ser una alternativa excluyente de la familia, ya que las asociaciones se formaron en estrecha relación con la familia, tal

${ }^{71}$ Ibidem, p. 386.

72 Tertullianus, Apologeticus 39, 10-12, CCL 1, 151-152.

${ }^{73}$ Cyprianus, Epistola 67, 6, CCL 36, 456457, trad.: Cipriano, Cartas, introducción, traducción y notas de M. Luisa García Sanchidrián, Madrid 1998, 463-468.

${ }^{74}$ Entre los autores de esta postura hay que mencionar: R.L. Wilken, Collegia, Philosofical Schools, and Theology, en: S. Benko - J.J. O'Rourke, The Catacombs and the Colosseum, Valley Forge 1971, 268-291; E. Judge, The social Pattern of Christian groups in the first century, London 1960, 63; F.M. De Robertis, Storia delle corporazioni e del regime associativo nel mondo romano, II, Bari 1973, 108; Meeks, Los primeros cristianos, 136-140. 
es, por ejemplo, el caso del „collegium quod est in domu Sergiae Paulinae"75. En las familias muy extensas, los señores promovían a veces la formación de un club y ofrecían un lugar de reunión como es el caso de la sociedad de entierros, que se reunía en la casa de Sergia Paulina.

Tanto los grupos cristianos como las asociaciones incorporaban a menudo a personas que ejercían la misma actividad comercial o artesanal. Ambos reservaban un espacio importante a las actividades rituales y de culto organizando banquetes comunes y otros actos fraternos. La provisión de sepultura propia y la conmemoración de los difuntos en los aniversarios constituían una función muy importante en muchas asociaciones. Desde los primeros tiempos del imperio surgen un gran número de asociaciones fúnebres, aceptadas por la ley. Los socios (sodales) prepararon una caja social, arca; se reunían mensualmente en una casa bajo la presidencia de su jefe magister collegii donde se trataban los asuntos relacionados con el collegium. Alquilaron un área sepulcral, que además de contener los sepulcros, tenían también los locales - domus, triclinia - para banquetes fúnebres.

La Iglesia de igual modo podría asumir la apariencia de una de las asociaciones similares. Tenemos que recordar que las asociaciones, collegia, se multiplicaron en la época de las persecuciones. El derecho de asociación ius coeundi, favorable desde el principio, encontró, sin embargo, un impedimento de celos por parte de algunos emperadores.

Según De Rossi los bienes inmuebles no pertenecían directamente a la Iglesia, sino a algunas asociaciones funerarias de gente pobre, es decir, a las collegia tenuiorum, que los cristianos habían formado en toda la ciudad y cuyos miembros se unían para asegurarse una sepultura digna. Tales colegios gozaban del favor por parte del poder imperial, porque, mientras que para las otras asociaciones era indispensable una autorización especial de una autoridad para su existencia, estos, en cambio, no la necesitaban ${ }^{76}$. Aquellas asociaciones, legalmente constituidas, tenían el derecho de poseer los bienes y lugares de reuniones de carácter religioso.

La palabra natalis por la que los gentiles designaban el aniversario del nacimiento de algunos que se honraba con aquella fiesta, fue usada por la Iglesia para señalar el aniversario de la muerte de un mártir. La inscripción de Lanuvium de 136, contiene una lista de los convidados a la fiesta de su collegio:

„VIII idus Martias natali Caesenni fratris

XIII L. Sept. natali caesenni fratris

XIX Ian. natali caesenni Rufini patroni municipi”77.

\footnotetext{
75 CIL VI 9148.

76 Cfr. De Rossi, Roma sotteranea, vol. I, 102.

77 La inscripción citada por O. Marucchi, Manuale di archeologia cristiana, Roma 933, 97.
} 
$\mathrm{Al}$ final de esa inscripción encontramos una nota que se refiere al banquete:

„Vini boni amphoras singulas, et panes as(sium) qui numerus collegi fuerit, et sardas (nu)mero quattuor, strationem caldam cum ministerio" 78 ,

Para aquellas fiestas y aquellos invitados eran conveniente las habitaciones, scholae, cellae, con todo el mobiliario necesario para las reuniones ${ }^{79}$.

En la antigua Cesarea de Mauritania, en Cherchell, encontramos dos célebres epigrafías en las cuales leemos que, un fiel, Evelpio, ha construido con sus gastos particulares una cella memoriae, ofreciéndola a la Iglesia, como tenían costumbre también los paganos, ofreciendo a un colegio una schola. Las dos inscripciones son las siguientes:

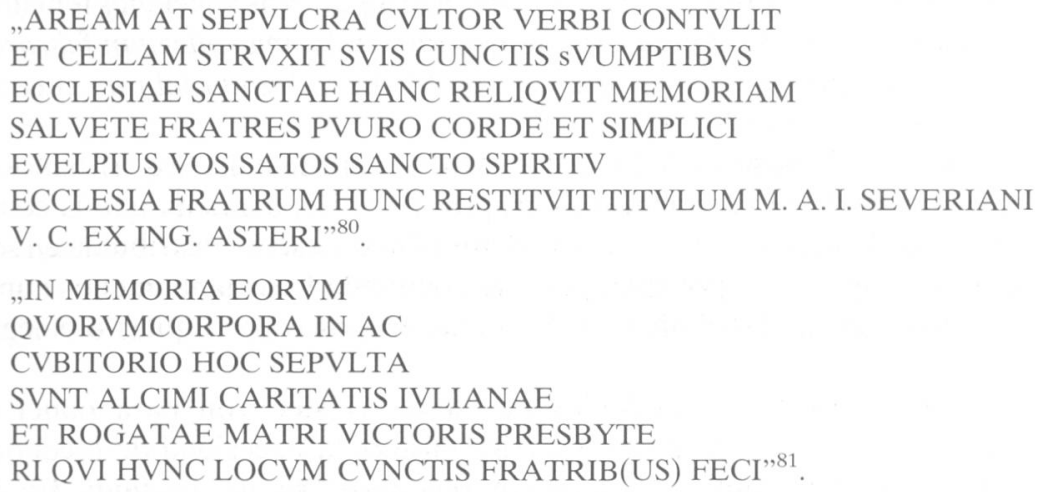

Estas epigrafías nos ofrece una información muy importante. El fiel Evelpio, que ha donado la cella se llama cultor verbi, como cultores Iovis, Herculis, Dianae, etc. De esta forma solían llamarse los adscritos a los colegios sodales paganos y, como dice Armellini, ellos asumían el nombre del colegio, Ecclesia fratrum $^{82}$.

La Iglesia, a partir del siglo III poseía ya los cementerios y lugares eclesiásticos, y podía utilizarlos para sus fines, según el derecho concedido por Trajano y Septimo Severo a las asociaciones fúnebres quibus coire licet. Esta teoría

\section{${ }^{78}$ Ibidem.}

79 En la entrada al cementerio de Domitila se encontraba un triclinio donde los cristianos tenían sus reuniones; cfr. M. Armellini, Antichi cemeteri cristiani, Roma 1983, 68; De Rossi, Roma sotteranea, p. 102.

${ }^{80}$ CIL VIII 9585.

81 CIL VIII 9586.

82 Cfr. Armellini, Antichi cemeteri, p. 69: „La fratellanza cristiana, il collegium che tale potea sembrare agli occhi dei gentili, assume qui quasi nome collegiale, quello di Ecclesia fratrum"; cfr. también G. Bovini, La propietà ecclesiastica e la condizione giuridica della chiesa in età precostantiniana, Milano 1949, 19-121. 
tenía muchos seguidores ${ }^{83}$; uno de ellos es Monti, quien opina, que los cristianos se organizaron en collegia tenuiorum no para refugiarse, sino legalmente, ya que las asociaciones cristianas gozaban de la presunción general de licitud que se otorgó a todas las asociaciones constituidas en virtud del senado consulto que favorecía a los tenuiores ${ }^{84}$.

Sin embargo, hay autores que no están en todo de acuerdo con la postura de De Rossi. Bovini ${ }^{85}$, por ejemplo, dice que los colegios funerarios comprendían pocos miembros, máximo cien, mientras que en la mitad del siglo III, la comunidad de Roma contaba con cerca de 40.000 miembros. Continuando, Bovini dice que aunque todos los colegios funerarios estuvieron compuestos de cien personas, tendríamos 400 colegios, y esto resulta poco probable. Ahora, mirando todo esto, hay que tener en cuenta, que algunas asociaciones tenían un número más elevado de miembros; por ejemplo, en Roma collegium fabrorum tignariorum comprendía 1500 miembros, en Milán collegium fabrum et centorianorum contaba con 1200 miembros.

Defendiendo la postura de De Rossi, Montini afirman que los cristianos de una misma ciudad podía formar más grupos. Además, comenta que la comunidad judía de Roma contaba con 50.000 miembros y estaba distribuida en sólo 13 colegios-sinagogas, „¿por qué, pues, la comunidad cristiana, menos numerosa, no podía estar distribuida en 25 o más grupos o parroquias o colegios funerales?" 86 .

Las persecuciones de mediados del siglo III sirvieron para poner de manifiesto la potencia y difusión del cristianismo, la necesidad de reconocer esa fuerza social y política, y también reconocer su ius coeundi. En los comienzos del siglo IV las iglesias poseían no sólo templos y cementerios, sino además otros bienes, que no figuraban a nombre de un individuo particular, sino al de la comunidad. A estos bienes hace referencia expresa el edicto de Milán:

„En atención a las personas de los cristianos, hemos decidido también lo siguiente: que los lugares suyos en que tenían por costumbre anteriormente reunirse y acerca de los cuales ya en la carta anterior enviada a tu santidad había otra regla, delimitada para el tiempo anterior, si apareciese que alguien los tiene comprobados, que los restituya a los mismos cristianos, sin reclamar dinero ni compensación alguna. Todo lo cual deberá ser entregado a la corporación de los cristianos, por lo mismo, gracias a tu solicitud, sin la menor dilación. Y como quiera que los mismos

83 Cfr. Th. Mommsen, Die Katacomben Roms, Bd. 1, Berlin 1871; G.M. Monti, I „,collegia tenuiorum" e la condizione giuridica della propietá ecclesiastica nei primi tre secoli del cristianesimo, en: Studi in onore di S. Riccobono, III, Bari 1933, 130-132; J. Coli, Collegia e sodalitates, Bologna 1913; H. Leclercq, Catacombes, DACL II 2, 2420.

${ }^{84}$ Cfr. Monti, I „,collegia tenuiorum”, p. 133-135.

85 Cfr. Bovini, La propietá ecclesiastica, p. 114-118.

86 G.M. Monti, Le corporazioni nell'Evo antico e nell'alto Medio Evo, Bari 1933, 266. 
cristianos no solamente tienen aquellos lugares en que acostumbraban a reunirse, sino que se sabe que también poseen otros lugares pertenecientes, no a cada uno de ellos, sino al derecho de su corporación, esto es, de los cristianos, en virtud de la ley que anteriormente ha dicho mandarás que todos estos bienes sean restituidos sin la menor protesta a los mismos cristianos, esto es, a su corporación, y a cada una de sus asambleas ${ }^{87}$.

2. Las asociaciones voluntarias. El primer período del Imperio Romano asistió a una abundancia de clubes, gremios y asociaciones de todo tipo. En el siglo II, los funcionarios romanos y los adversarios literarios del cristianismo identificaban a menudo a los grupos cristianos con tales clubes, especialmente con las reuniones secretas, que eran consideradas como focos de inmoralidad y llegaron a estar prohibidas:

„Por tanto, no procedía tampoco, si quería usarse de un poco de lenidad, contar entre las facciones ilícitas a esta «secta», la que nada hace de cuanto suele temerse de las facciones prohibidas. Y es que, si no me equivoco, la causa de prohibirse las facciones es el proveer por el orden público, a fin de que la sociedad no se divida en partidos, los que fácilmente turbarían los comicios, las asambleas populares, las curias, los mismos espectáculos, por el choque de apetencias rivales cuando ya los ciudadanos habían comenzado a traficar con el concurso de su violencia vanal y mercenaria. Mas en cuanto a nosotros, a quienes la pasión de gloria y de honores nos deja fríos, nada nos es tan indiferente como la cosa pública. Una sola República conocemos a todos común: el mundo" 88 .

Tanto las asociaciones privadas como los grupos cristianos dependían, en buena medida, de la generosidad de personas ricas que ejercían la función de patrocinadores. El collegium protegido recompensaba a su patrocinador con inscripciones glorificadoras, títulos honoríficos y guirnaldas, quizá con una estatua y con un control eficaz sobre la vida del club, ya que no había poderes compensatorios fuertes en las asociaciones. En este aspecto la comunidad cristiana era muy distinta, y los patrocinadores podían tener motivo para sentirse algo menospreciados. San Pablo exhorta a los Corintios a mostrar un poco más de respeto hacia tales personas, como Estéfanas, Fortunato o Acacio: „Otra cosa os pido, hermanos; ya conocéis la familia de Estéfanas y sabéis que han sido los primeros cristianos de Acaya y que se han consagrado por entero al servicio de los creyentes; pues haríais muy bien en poneros a su disposición y a la de todo el que se afane y trabaje en la misma tarea. Estoy lleno de gozo con la visita de Estéfanas, Fortunato y Acacio, que han llenado el vacío de vuestra ausencia, y han tranquilizado mi espíritu y vuestro. Debéis estar reconocidos a tales personas" (1Cor 16, 15-18).

${ }^{87}$ Eusebius HE X 5, 9-11, SCh 55, 106-107.

${ }^{88}$ Tertullianus, Apologeticus 38, 1-3, CCL 1, 149. 
Por otra parte, los collegia mantenían al menos la apariencia de un gobierno interno democrático imitando a la polis clásica. Había también notables diferencias entre los grupos cristianos y las típicas asociaciones voluntarias convencionales. Sobre todo, los grupos cristianos eran exclusivistas y absorbentes en un grado incomparable con cualquier asociación cultual pagana. Por otra parte, los grupos cristianos eran mucho más complejos en término de estratificación social y de otras categorías sociales que las asociaciones voluntarias. A veces se franqueaban las barreras sociales en las asociaciones, especialmente bajo la influencia romana donde las listas de miembros y de funcionarios incluían a menudo a hombres y mujeres, o a libertos, libres y esclavos. Sin embargo, hay poca evidencia de que existiera una igualdad de roles entre estas categorías, por eso los clubes tendían a reunir personas que fuesen socialmente homogéneas ${ }^{89}$.

Las asociaciones cristianas no se inspiraron directamente en el modelo de las asociaciones paganas, aunque en la literatura posterior se llama a veces al grupo cristiano Өıóoos, factio, curia, corpus. San Pablo emplea el verbo ovváyeıv sólo una vez, para referirse, no a la fundación de un grupo, sino a una reunión para un fin específico ${ }^{90}$, y nunca el sustantivo correspondiente, synagoge. Por otra parte, tampoco se puede encontrar en los títulos de clubes

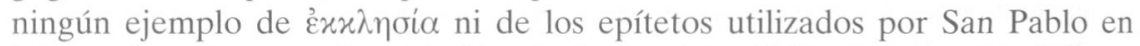

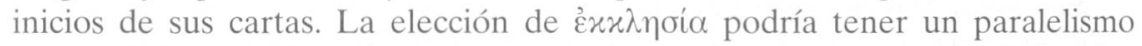
estructural en el lenguaje de las asociaciones, porque éstas solían imitar los términos técnicos de la estructura de la ciudad republicana, y el uso más

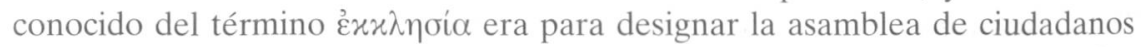
libres de Atenas y de otras ciudades de constitución griega. No obstante, los únicos posibles títulos que eran comunes a las asociaciones son غ̇ंıoxóлos (Flp $1,1)$ y dıxxóvos (Flp 1, 1; Rom 16,1) ${ }^{91}$.

3. Los colegios presbiterales en la Iglesia primitiva. Collegium por antonomasia es el de los pontífices, y a su ejemplo se modelan todos los otros collegia religiosos, y aún los puramente seculares. Por eso, cerrando ese bloque de las asociaciones, nos ocuparemos ahora de los colegios presbiterales en la época apostólica y postapostólica.

a. La é p oc a a postólica. El primer colegio presbiteral lo encontramos en Jerusalén. Los Hechos de los Apóstoles narrando las circunstancias de la institución de los Siete, guardan silencio sobre el origen de los presbíteros;

89 Cfr. Meeks, Los primeros cristianos, p. 138.

${ }^{90}$ Cfr. 1Cor 5, 4: „Reunido en espíritu con vosotros, en nombre y con el poder de nuestro Señor Jesucristo".

91 Cfr. Meeks, Los primeros cristianos, p. 139. 
éstos aparecen ya como existentes cuando la Iglesia de Antioquía les remite el dinero destinado a las víctimas del hambre que asolaba entonces Judea (Hch 11,30). Los presbíteros se nos presentan como depositarios y administradores de aquella colecta. Pero vemos ejercer otra función a los presbíteros en el concilio de Jerusalén, donde aparecen con categoría de jueces y, en unión con los apóstoles, resuelven la controversia sobre la obligatoriedad de la Ley y de la circuncisión.

En la comunidad cristiana de Jerusalén se fue formando progresivamente la conciencia de construir ya un pueblo nuevo, distinto del antiguo. Esta conciencia apareció en la comunidad cuando ésta se vio perseguida por las autoridades de su propia nación y cuando muchos judíos rechazaron la nueva predicación. Los términos usados para designar a los dirigentes de la nueva institución no repiten ninguno de los términos esenciales de la constitución judía, excepto el de presbíteros. Los nuevos jefes no son llamados sacerdotes, y Pedro, el primero entre ellos, nunca se designa con el término de sumo sacerdote. En la nueva comunidad, el nombre de los jefes de rango más alto es el de Doce, de Apóstoles. Por el momento no se pensó en adoptar las viejas denominaciones para designar las instituciones que en la nueva comunidad estaban sustituyendo a las antiguas. A semejanza de los ancianos de Israel, los presbíteros de la comunidad cristiana de Jerusalén figuran entre los miembros del cuerpo que dirige la comunidad ${ }^{92}$.

Fuera de Jerusalén, Pablo y Bernabé instituyen presbíteros en la comunidad que nace durante su primer viaje ${ }^{93}$. Parece que al aludir a estos hechos el relato quiere decir que Pablo y Bernabé, con ese nombre, pretendieron dar dirigentes a las nuevas comunidades. Durante su tercer viaje, de regreso a Jerusalén, Pablo manda llamar a los presbíteros de la comunidad de Éfeso:

„Desde Mileto, mandó a buscar a los responsables de la iglesia de Éfeso. Cuando llegaron, les dijo: Vosotros sabéis cómo me he comportado con vosotros todo el tiempo desde el primer día de mi llegada a la provincia de Asia" (Hch 20, 17-18).

Éstos se presentan como un cuerpo de presbíteros-episcopoi, puestos por el Espíritu Santo para apacentar la Iglesia de Dios. El mismo esquema de funciones, principalmente de presbíteros-maestros, aparece como propio de los colegios presbiterales que se constituyen en Creta. Cada presbítero-obispo es ecónomo de Dios, deberá exhortar con sana doctrina, amonestar a los que contradicen, vigilar sobre la doctrina heterodoxa: „Te he dejado en Creta para que acabes de organizarlo todo y establezcas presbíteros en cada ciudad,

92 Cfr. G. D'Ercole, Los colegios presbiterales en los origenes de la Iglesia, „Concilium” 1966, nr $15-17,362-363$.

${ }^{93}$ Cfr. Hch 14, 23: „Designaron responsables en cada iglesia y, después de orar y ayunar, los encomendaron al Señor, en quien habían creído". 
siguiendo las instrucciones que te di: que sean irreprochables, que se hayan casado una sola vez, que sus hijos sean fieles y no puedan ser tachados de mala conducta o de insubordinación" (Tit 1, 5-6).

Más explícita aún es la primera carta de Pedro sobre la tarea de apacentar que corresponde a los colegios presbiterales: „Apacentad el rebaño que Dios os ha confiado, no a la fuerza, sino de buen grado, como Dios quiere; y no por los beneficios que pueda reportaros, sino con ánimo generoso; no como déspotas con quienes os han sido confiados, sino como modelos del rebaño" (1Pe $5,2-3)$. Parece que al constituir los presbíteros, tuvieron presente las instituciones judías de Palestina y de la Diáspora.

b. La época postapostólica. En Corinto, en tiempos de Clemente Romano, hay un colegio de presbíteros cuyo oficio principal es una $\lambda \varepsilon \iota \tau o v \varrho \gamma i \alpha$, mediante la cual sirven a la grey de Dios:
„Y es así que cometeremos un pecado nada pequeño si deponemos de su puesto de obispos a quienes intachable y religiosamente han ofrecido los dones. Felices los ancianos que nos han precedido en el viaje a la eternidad, los cuales tuvieron un fin fructuoso y cumplido, pues no tienen ya que temer que nadie los eche del lugar que ocupan. Lo cual decimos porque vemos que vosotros habéis removido de su ministerio a algunos que lo honraron con conducta santa e irreprochable" ${ }^{94}$.

Como vemos, San Clemente nos da el testimonio de que estos presbíteros han trabajado santamente y sin tacha.

Una de las fuentes principales para el conocimiento de los colegios presbiterales son las cartas de Ignacio de Antioquía. En ellas aparece con

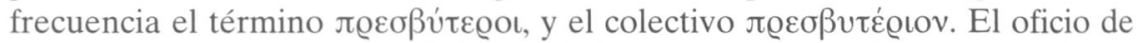
presbítero se presenta especialmente bajo el aspecto colegial de un conjunto

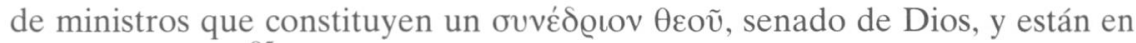
torno al obispo ${ }^{95}$. Ignacio dice que el presbiterio de Magnesia es digna corona espiritual de su obispo; el de Éfeso está unido al obispo como las cuerdas a la lira, es una sola cosa con el obispo y los diáconos, como uno en el altar $^{96}$. Los presbíteros, con el obispo primero y con los diáconos después, son elementos esenciales de la comunidad; sin ellos no se puede hablar de Iglesia $^{97}$.

También Policarpo nos presenta a los presbíteros como un colegio que, con el obispo y los diáconos, constituyen la cabeza de la comunidad. Así describe su oficio:

94 Clemens Romanus, Epistola ad Corinthios 44, 4-6, ed. D. Ruiz Bueno, Padres Apostólicos, BAC 65, Madrid 1965, 218.

95 Cfr. Ignatius Antiochenus, Epistola ad Trallianos 2, 1, ed. BAC 65, 596.

96 Cfr. idem, Epistola ad Philadephios 4, ed. BAC 65, 593.

97 Cf. idem, Epistola ad Ephesios 2, 2, ed. BAC 65, 585. 
„Más también los ancianos han de tener las entrañas de misericordia, compasivos para con todos, tratando de traer a buen camino lo extraviado, visitando a todos los enfermos; no descuidándose de atender a la viuda, al huérfano y al pobre; atendiendo siempre al bien, tanto delante de Dios como de los hombres, muy ajenos de toda ira, de toda acepción de personas y juicio injusto, lejos de todo amor al dinero, no creyendo demasiado aprisa la acusación contra nadie, no severos en sus juicios, sabiendo que todos somos deudores de pecado" 98 .

De otros colegios presbiterales tenemos testimonios en las epístolas de San Cipriano. En ellas tenemos la noticia de dos colegios presbiterales: primero en Cartago y, segundo en Roma. Las cosas que se tratan en las cartas son las siguientes: la suplencia en el gobierno de la Iglesia de Cartago por parte de los presbíteros debido a la ausencia del obispo:

„Confiando no sólo en vuestro afecto sino también en vuestro espíritu religioso, os aconsejo y encargo por la presente que seáis vosotros, cuya presencia ahí no hace recelar ni es excesivamente peligrosa, quienes me supláis en todo lo que exige el gobierno de nuestra religión"99;

La conducta para la celebración eucarística entre los confesores, con advertencias especiales a los presbíteros, a los que se ordena celebrar individualmente, sin asistencia del pueblo, para evitar perturbaciones ${ }^{100}$; el nombramiento de algunos miembros del clero:

„En las ordenaciones de clérigos, carísimos hermanos, solemos consultaros con anticipación y examinar juntos la vida y méritos de cada uno" ${ }^{101}$.

„Conviene que sepáis que he ordenado lector a Sáturo, subdiácono al confesor Optato, a los que ya hace tiempo, de común acuerdo, habíamos aproximado al clero, ya que por una parte a Sáturo más de una vez le encargamos la lectura en el día de la Pascua, y por otra últimamente al examinar a los lectores cuidadosamente con los presbíteros instructores, ordenamos a Optato como lector para instruir a los catecúmenos" ${ }^{102}$.

En Roma, fue el mismo colegio presbiteral al que Cipriano envió primero una carta en la que daba su parecer sobre la disciplina que era preciso adoptar con los lapsi. San Cipriano se preocupa de modo particular por la solidaridad con el colegio presbiteral de Roma, por eso envía a aquellos presbíteros una serie de documentos con los que muestra que ha seguido su parecer en las cuestiones de la penitencia:

98 Polycarpus, Epistola ad Philippenses 6, 1, ed. BAC 65, 265-266.

99 Cyprianus, Epistola 14, 2, CCL 3B, 80, trad. M. Luisa García Sanchidrián: San Cipriano, Cartas, Madrid 1998, 79-84.

100 Cfr. idem, Epistola 5, 2.

101 Idem, Epistola 38, 1, CCL 3B, 183, trad. M. Luisa García Sanchidrián, p. 183-185.

102 Idem, Epistola 29, CCL 3B, 138, trad. M. Luisa García Sanchidrián, p. 137-138. 
„Dispuse que se dilatasen del todo las causas de los demás, y que se reservasen para el tiempo en que yo esté presente, a fin de que cuando, una vez concedida la paz por el Señor, nos reunamos varios obispos, podamos, consultando también vuestro parecer, disponerlo todo o reformarlo" ${ }^{103}$.

Concluyendo, hay que decir, de que una de las estructuras que corresponde a la tendencia del hombre a reunirse para conseguir un objetivo común en e mundo romano, eran las asociaciones. En la época imperial las asociaciones quedaron divididas en dos categorías: los collegia licita y los collegia illicita. El término illicitus se aplicaba a las asociaciones constituidas sin autorización y aquellas que aún habiendo sido autorizadas, pudieran tener algún peligro implícito. Un tipo peculiar de las asociaciones eran collegia tenuiorum (collegia funeraticia). Muchos clientes y esclavos de las familias ricas no podían soportar los gastos de una tumba. Se agregaban, pues, a las grandes sepulturas y mausoleos de sus patronos. Las cosas cambiaban cuando los patronos no eran ricos y no podían cubrir los gastos de una tumba. Muchos tenuiores quedaban sin sepultura. Por eso, los colegios funerarios tenían como objetivo fundamental proporcionar a sus miembros una sepultura digna. Parece pues que las comunidades cristianas adoptaron, por lo menos en la primera fase, la forma de collegia tenuiorum como una forma de escudo legal de su existencia. Los colegios cristianos aparecen como las asociaciones de carácter religioso. Los grupos cristianos como las asociaciones privadas dependían, en buena medida, de la generosidad de personas ricas que ejercían la función de patrocinadores.

\section{STOWARZYSZENIA CHRZEŚCIJAN W KOŚCIELE PIERWOTNYM}

(Streszczenie)

W naturze człowieka jest zakorzeniona tendencja do zrzeszania się, po to, by osiągnąć wspólne cele. Pośród Rzymian to dążenie było manifestowane już od czasów monarchii i identyfikowało się w zakładaniu stowarzyszeń - collegia.

Religia była jednym z fundamentalnych motywów zakładania stowarzyszeń. Stąd nie brakowało religijnych grup (collegia, amicitia, convictus, curia, magisterium, schola, sodalitium, etc.), które dysponowały miejscem sprawowania kultu oraz

103 Idem, Epistola 20, 2, CCL 3B, 107, trad. M. Luisa García Sanchidrián, p. 106-110. 
miały swoją strukturę hierarchiczną. W Imperium Rzymskim nie brakowało także stowarzyszeń pogrzebowych - collegia tenuiorum. Tenuiores, byli to ludzie dysponujący niewielkimi zasobami ekonomicznymi, którzy zrzeszali się, czcząc jakieś bóstwo i zapewniając sobie w ten sposób godny pochówek. Do stowarzyszeń pogrzebowych zaliczano także collegia domestica. Należeli do nich niewolnicy i libertyni bogatych rodzin, którzy płacąc miesięczne składki do wspólnej kasy i czcząc bożki larów, zapewniali sobie pochówek we wspólnym miejscu. Collegia chrześcijańskie pojawiają się także jako stowarzyszenia o charakterze religijnym. Nie brak autorów, jak m.in. Wilken, Benko czy De Rossi, którzy uważali, że pierwsze grupy chrześcijańskie imitowały model stowarzyszeń pogrzebowych. Kościół począwszy od III w. posiadał cmentarze i domy, które mógł wykorzystywać dla swoich celów. Większość grup chrześcijańskich w dużej mierze było jednak uzależnionych od osób bogatych, którzy pełnili funkcje patronów.

Mówiąc o stowarzyszeniach w pierwszych wiekach chrześcijaństwa, nie sposób pominąć stowarzyszeń kapłańskich. Pierwsze z nich spotykamy w Jerozolimie. Dzieje Apostolskie opowiadając okoliczności powołania „Siedmiu”, milczą na temat pochodzenia prezbiterów. Ci pojawiają się, kiedy Kościół antiocheński przekazuje im pieniądze dla ofiar głodu, jaki panował wówczas w Judei. Prezbiterzy jawią się jako depozytariusze i administratorzy owej kolekty. Na soborze w Jerozolimie prezbiterzy wykonują także funkcję sędziów rozstrzygających sporne kwestie. Z kolei w epoce po-apostolskiej jawią się oni jako senat Boży i otaczają biskupa.

Stowarzyszenia, w jakich zrzeszali się pierwsi chrześcijanie, nie były strukturą nową w znaczeniu oryginalności, nie były czymś wymyślonym przez chrześcijan. $\mathrm{Ci}$ jednak dokonując ich adaptacji, nadali im nowy wymiar. 